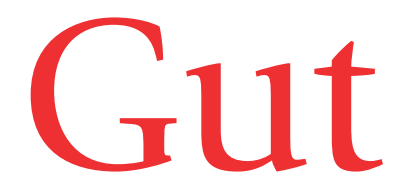

\title{
Editorial
}

\section{Retractions in Gut 10 years after publication}

It is with great regret that I include in this issue of the journal a retraction order for a paper authored by Dr Anjan Banerjee and Professor Tim Peters, which was published in Gut in 1990 when they were employed by King's College Hospital. Dr Banerjee wrote to me immediately following the decision by the Professional Conduct Panel of the General Medical Council (GMC) that he had been found guilty of serious professional misconduct and had been suspended for a period of 12 months. He indicated that he wished to retract the paper written by himself and Professor Tim Peters, "Experimental non-steroidal anti-inflammatory drug induced enteropathy in the rat - similarities to inflammatory bowel disease and effect of thromboxane synthetase inhibitors" (Gut 1990;31:1358-64) in which it was judged that he had falsified data. He also indicated that he wished to retract an abstract "Sulphasalazine reduces indomethacin induced changes in small intestinal permeability in man" (Banerjee A, Sherwood R, Rennie JA, Peters TJ. Gut 1990;31:A593) which had been published in Gut as part of the proceedings of the Spring British Society of Gastroenterology (BSG) meeting in Warwick 1990. However, Dr Banerjee and colleagues had indicated to the BSG that they wished to withdraw this abstract before the meeting took place and, although it was not presented at the meeting, the copy had already gone to press and therefore appeared in the journal. Thus for 10 years these reports, now deemed to contain falsified data, have remained within the biomedical literature.

This is clearly a personal tragedy for the authors, and has been potentially harmful to the development of scientific ideas which could have ultimately affected patient care. This case, however, perhaps raises more questions than answers. Why has it taken a decade before the record has been put straight? I believe it is true to say that rumours about this case had rattled around the corridors of a number of institutions for many years. Some members of the BSG are thought to have known of the allegations, as did some colleagues at Northwick Park Hospital, King's College Hospital Medical School, and some members of staff at the University of London. Why was this not fully explored in the early 1990s?

An internal inquiry was held at King's College Hospital Medical School which apparently reported in 1991. It is alleged that the inquiry produced evidence to suggest that Banerjee's research findings from 1988-91 were "at best unreliable and in many cases spurious". "However no action was taken, even though it could be argued that the case should have been reported to the GMC at that stage. It became clear at Banerjee's recent hearing at the GMC that his laboratory workbook, an important item of primary evidence, went missing after the inquiry and was probably destroyed by the authorities at King's. In retrospect, this is a disaster and does nothing to increase public confidence in the ability of the medical profession to regulate itself. For the man in the street, this can only be viewed as a "cover up".

How did this story eventually come to light? As in many other cases of research fraud it is the persistence of a "whistle blower" that enables the case to be brought into the public domain. Peter Wilmshurst, consultant cardiologist in Shrewsbury, wrote an article in The Lancet in 1997 which he entitled "The code of silence". ${ }^{1} \mathrm{He}$ wrote about his personal experiences of detecting and reporting research misconduct, one of which was the Banerjee case. The case description was "coded" for legal reasons but for those who were aware of the circumstances it was easily recognisable. The main thrust of the piece was the failure of the profession to investigate miscreants who had breached the rules of research ethics. In particular it was the closing of ranks, often involving senior members of the profession, that drove him on. Wilmshurst's commitment to outing fraudsters began in his early days as a clinical research fellow at a London Teaching Hospital where he experienced first hand corruption in clinical research. I understand from Peter Wilmshurst that he has reported other cases to the GMC which are still waiting to be heard.

This could sound like a satisfactory ending to an otherwise sad story. However, a number of issues remain unresolved. As editor of the journal in which Banerjee published his fraudulent work, I am responsible for issuing a retraction notice in the journal-a request which came promptly from the author following the GMC judgement. However it is extremely difficult to effectively erase an article from the published literature as the March and November 1990 issues of Gut will remain on library shelves for many decades to come without any indication that the Banerjee paper is fraudulent. In addition, we know that retracted papers continue to be cited after retraction almost invariably without reference to the falsehoods that are contained therein. ${ }^{2}$ If publication of scientific material becomes solely electronic, only then will it be possible to completely erase a paper and put the record straight.

Another issue is the delay that has occurred in bringing this case to the GMC. Intuitively most of us would believe that it would be preferable to deal with cases of research fraud promptly to limit the damage that false biomedical data might cause and to minimise the risk that further misdemeanours might be committed. Banerjee had already been suspended earlier in 2000 by his NHS Trust for, I understand, a totally different reason and has recently resigned from this post. Whether earlier resolution of the research misconduct case would have influenced this other issue remains a matter for speculation.

Unfortunately the case does not rest here. Banerjee's supervisor at the time he produced the fraudulent work, Professor Tim Peters, is also to appear before the GMC in 
early 2001 when his role in the affair will presumably be examined. ${ }^{3}$ Finally, and perhaps most important of all, it must be determined what happened following the internal enquiry of the Banerjee case at King's College Hospital Medical School in 1991. If Banerjee's work-as it is alleged-was found to be questionable at that time, why did the Dean of the day not refer the case to the GMC immediately? Why was the Gut paper not retracted in 1991, and why did Banerjee's supervisor remain associated with the work when other collaborators withdrew their names from the paper? It is likely that answers to all or some of these questions will come out of Professor Peters's GMC hearing; perhaps the GMC will have more work to do as the story evolves even further.

There is yet another matter still to be resolved. Data included in the retracted Gut paper allegedly form part of Banerjee's Master of Surgery thesis awarded by the University of London in $1991 .^{2}$ I tried to obtain a copy of the thesis from the University to verify whether this was indeed the case, but it was missing from the shelves, apparently out on an "inter-library loan". I was advised to try the library at St Thomas's. Another whistle blower (not Wilmshurst) apparently advised the University of London at the time, in writing, alleging falsification of the thesis, but was subsequently instructed to withdraw the letter with warnings that this might damage future career prospects. This story is almost too difficult to believe; it is perhaps surprising that this additional problem was not dealt with at the recent GMC hearing.

The Banerjee case illustrates a number of important deficiencies in the way in which we handle alleged cases of research misconduct in the UK. Firstly, it is evident that it is relatively simple to fabricate data and get it published in a reputable medical journal. In the majority of cases it will be virtually impossible for reviewers and editors to identify fraudulent material. Detection in this case, and in many others will almost always depend on the willingness of a vigilant whistle blower to speak out. There is little to gain for whistle blowers, particularly when their comments fall on deaf ears, or they are threatened with professional extinction. Secondly, the case demonstrates the potential weakness of the internal inquiry. Although it is unclear as to the location of the final resting place of the King's Banerjee Report, it is alleged that its findings were not in Banerjee's favour. ${ }^{1}$ It then took almost a decade and the persistent efforts of an external whistle blower, who had no conflicting interests, to bring the case to the GMC. This cannot be regarded as a satisfactory state of affairs and will do nothing to reassure the public that the medical profession is still fit to self regulate. The case also shows the importance of the role of the research supervisor as a custodian of research quality. When it was clear in 1991 that Banerjee's work was suspect, why did he not withdraw his support and insist on an external review by the GMC?

This case, and indeed many others considered by the Committee for Publication Ethics (COPE) ${ }^{45}$ and probably others still in the GMC pipeline, convinces me that the procedures currently in place in the UK are inadequate to deal with many of the alleged cases of research misconduct. COPE has campaigned for more than three years for an independent body to consider such cases. ${ }^{6}$ Although many Universities and Medical Schools have written guidance as to how to pursue an internal review, I have concerns that a lack of independence may inhibit action of the naturally reluctant whistle blower and not provide appropriate protection when required. In October 1999 a consensus conference was held at the Royal College of Physicians in Edinburgh on Misconduct in Biomedical Research. The consensus panel recommended that a National Panel should be established which would develop and promote models of good practise for local implementation, provide assistance with the investigation of alleged research misconduct, and collect, collate, and publish information on the incidence of research misconduct. Although discussions have taken place and a report is said to be in preparation, no clear action has at yet become apparent to those of us on the outside. ${ }^{7}$ Even if such an advisory panel is established will it really have the teeth to ensure that we do not have a re-run of the Banerjee case? I have my doubts. ${ }^{8}$ What COPE is proposing is not new. The USA, Nordic countries, and others have had external agencies in place to deal with alleged cases of research misconduct for almost 10 years $^{9}$; why is the UK lagging behind? One is reminded of the fact that it took 20 years longer to establish Research Ethics Committees in Britain than it did in the USA! $!^{10}$

MICHAEL J G FARTHING Editor

fanuary 2001

1 Wilmshurst P. The code of silence. Lancet 1997;349:567-9.

2 Ferriman A. Consultant suspended for research fraud. BMF 2000;321:1429.

3 Budd JM, Sievert ME, Schultz TR. Phenomena of retraction. $7 A M A 1998$; 280:296-7.

4 Committee on Publication Ethics. Annual Report 1998. London: BMJ Publishing Group, 1998.

5 Committee on Publication Ethics. Annual Report 1999. London: BMJ Publishing Group, 1999.

6 Farthing MJG. An editor's response to fraudsters. BMF 1998;316:1729-31.

7 White C. Plans for tackling research fraud may not go far enough. BMf 2000;321:1487.

8 Farthing M, Horton R, Smith R. UK's failure to act on research misconduct. Lancet 2000;356:2030.

9 Nylenna M, Andersen D, Dahlquist G, et al. Handling of scientific dishonesty in the Nordic countries. Lancet 1999;354:57-61.

10 Doyal L, Tobias JS, Eds. Informed consent in medical research. London BMJ Publishing Group, 2000.

\section{Retraction}

Gut is retracting the paper by AK Banerjee and TJ Peters, "Experimental non-steroidal anti-inflammatory drug induced enteropathy in the rat-similarities to inflammatory bowel disease and effect of thromboxane synthetase inhibitors" (Gut 1990;31:1358-64) and the abstract AK Banerjee, R Sherwood, JA Rennie and TJ Peters, "Sulphasalazine reduces indomethacin induced changes in small intestinal permeability in man" (Gut 1990;31:A593) at the request of Dr Banerjee. At the end of November 2000, the General Medical Council found Dr Banerjee guilty of serious professional misconduct and suspended him for 12 months. Both articles were deemed to contain information which was deliberately falsified. 